\title{
Sobre las epistemologías enmarcadas en los imaginarios sociales frente al turismo rural-indígena.
}

\author{
About epistemologies framed in social imaginaries in front of rural- \\ indigenous tourism.
Sobre epistemologias enquadradas nos imaginários sociais na frente do turismo rural-indigena.

\author{
Rebeca Osorio González ${ }^{1}$ \\ ${ }^{1}$ Facultad de Turismo y Gastronomía (UAEM), Toluca de Lerdo, México.
}

Palabras clave:

Epistemologías;

Imaginarios sociales;

Comunidad local o receptora y turismo rural-indígena.

\section{Resumen}

Los imaginarios sociales se han analizado desde diferentes campos de investigación como la socio logía, antropología, geografía, historia y el psicoanálisis. Sin embargo, para la dimensión turística no hay análisis o antecedentes de investigación que permitan conocer la forma en la que los estudios turísticos, harían uso de teorías sobre imaginarios sociales para dar cuenta de una temática propia, particularmente enfocada en la comunidad local y no en los turistas. Este artículo busca mostrar algunas posturas e investigaciones respecto a los imaginarios y esbozar una primera propuesta, para un posterior abordaje desde la comunidad receptora, actor clave en el desarrollo de la actividad turística en el medio rural. En este sentido, se retoman conceptos centrales desde Edmund Husserl, como las habitualidades y lo social instituido de Cornelius Castoriadis, con el fin de dirigirlos al análisis de los imaginarios sociales, en tanto experiencias de las comunidades receptoras frente al turismo rural-indígena. Así los enfoques vía los cuales se han analizado los imaginarios sociales, desde las ciencias cognitivas, las historiográficas, las antropológicas, y en general las ciencias sociales, en estas últimas con especial atención al turismo, desde su actor más mediático: el turista, poseen ciertos matices que permiten encontrar similitudes pero también dilucidar diferencias, mientras unos conceptualizan los imaginarios como imágenes mentales, otros argumentan que son objetivables a través de elementos tangibles, estáticos e institucionalizados. Sin embargo, los imaginarios intersubjetivos que se quieren demarcar en este artículo, parten del supuesto de que estos son concepciones dinámicas del mundo y de la realidad que forma el entorno histórico de sujetos concretos, que incursionan y están envueltos en las dinámicas de la actividad turística, más allá de las simples evocaciones estáticas y analíticas con las que comúnmente se delimitan a los imaginarios.

Abstract

Keywords:

Epistemologies;

Social imaginaries;

Local or receiving community and rural-indigenous tourism.
Social imaginaries have been analyzed from different fields of research such as sociology, anthropology, geography, history and psychoanalysis. However, taking into consideration the tourist dimension, there is no analysis or research background that allows to know the way in which tourist studies would use theories on social imaginaries to account for a topic of their own, particularly focused on the local community and not on tourists. This article seeks to show some positions and research regarding the imaginaries and outline a first proposal, to address them from the receiving community. In this sense, central concepts are taken up from Edmund Husserl, such as the habitualities and the social instituted by Cornelius Castoriadis in order to direct them to the analysis of social imaginaries, as experiences of the receiving communities versus rural tourism-indigenous. The approaches through which social imaginaries have been analyzed, from the cognitive sciences, historiographic, anthropological, and in general the social sciences, have certain nuances that allow to find similarities but also to elucidate differences, while some conceptualize imaginaries as mental images, others argue that they are objectionable through tangible, static and institutionalized elements. However, the intersubjective imaginaries that we want to highlight in this proposal start from the assumption that these are dynamic conceptions of the world and of the reality that form the historical environment of concrete subjects, beyond the simple static and analytic evocations that imaginaries are 
commonly delimited.

Palavras-chave:

Epistemologias; Imaginários sociais;

Comunidade local ou anfitriã e turismo rural-indígena.

\section{Resumo}

Os imaginários sociais foram analisados a partir de diferentes campos de pesquisa, como sociologia antropologia, geografia, história e psicanálise. No entanto, para a dimensão turística não há análise ou antecedentes de investigação que permitam conhecer a forma como os estudos turísticos, fariam uso de teorias sobre imaginários sociais para dar conta de uma temática própria, particularmente focada na comunidade local e não em turistas. Este artigo procura mostrar alguns posicionamentos e pesquisas sobre os imaginários e traçar uma primeira proposta, para posterior aproximação da comunidade de acolhimento, ator fundamental no desenvolvimento da atividade turística no meio rural. Nesse sentido, são retomados conceitos centrais de Edmund Husserl, como as habitualidades de Cornelius Castoriadis e o social instituído, a fim de direcioná-los à análise dos imaginários sociais, como experiências das comunidades hospedeiras frente ao turismo rural-indígena. Assim, as abordagens através das quais têm sido analisados os imaginários sociais, desde as ciências cognitivas, historiográficas, antropológicas, e em geral as ciências sociais, nestas últimas com especial atenção ao turismo, desde o seu ator mais mediático: o turista, têm certas nuances que permitem encontrar semelhanças, mas também diferenças elucidativas, enquanto alguns conceituam os imaginários como imagens mentais, outros argumentam que eles são objetificáveis por meio de elementos tangiveis, estáticos e institucionalizados. Porém, os imaginários intersubjetivos que queremos demarcar neste artigo partem do pressuposto de que se trata de concepções dinâmicas do mundo e da realidade que conformam o ambiente histórico de sujeitos específicos, que entram e estão envolvidos na dinâmica da atividade turística, além das simples evocações estáticas e analíticas com as quais os imaginários são comumente delimitados.
Recebido em: 15/04/2021.

Aprovado em: 04/10/2021.

Leandro B. Brusadin.

Como citar: González, R. O. (2022). Sobre las epistemologías enmarcadas en los imaginarios sociales frente al turismo rural-indígen. Revista Brasileira de Pesquisa em Turismo, São Paulo, 16, e-2422. http://doi.org/10.7784/rbtur.v16.2422

\section{INTRODUCCIÓN}

Los estudios que utilizan la noción de imaginarios turísticos, en su mayoría trabajan sus análisis desde la perspectiva del turista, olvidando la dimensión local, es decir de la comunidad receptora y en el caso del turismo rural-indígena, la comunidad originaria, aunque esta última es un actor clave en las dinámicas turísticas, ya sea porque son los personas con las que interactúa el turista, por formar parte del sistema turístico, debido a que en algunos casos son ellos los prestadores de servicios turísticos, por ser dueños de los atractivos que el turista disfruta y en el caso del turismo rural-indígena per se la propia comunidad y su cotidianidad, es el motivo para generar el desplazamiento. Por ello es necesario construir otras propuestas epistemológicas, desde donde sea más adecuado abordar los imaginarios sociales en comunidades indígenas, inmersas en dinámicas turísticas.

En consecuencia, es preciso hacer un recorrido, aunque sin pretensiones de exhaustividad, desde los principales autores que han trabajado imaginarios en lo social, geográfico, histórico, turístico, espacial e incluso desde el psicoanálisis.A la par es pertinente revisar en que sentido estos autores abonan o no, a una primera propuesta que se sigue trabajando sobre imaginarios intersubjetivos versus imaginarios instituidos, en el marco de la inserción de la comunidad local en actividades de turismo rural-indígena. Por tanto, el artículo esta dividido en tres grandes apartados: Epistemologías enmarcadas en los imaginarios; Invocando otras posibilidades para el estudio de los imaginarios y la sección de Conclusiones.

\section{EPISTEMOLOGÍAS ENMARCADAS EN LOS IMAGINARIOS}

En las ciencias cognitivas uno de los principales exponentes es el alumno de Sigmund Freud, Jacques Lacan, a través de su tríada sobre: Lo real, simbólico e imaginario, donde esta tríada nos remite al estadio del espejo, como una identificación en el sentido pleno que el análisis da a este término: a saber, la transformación producida en el sujeto cuando asume una imagen. La función del estadio del espejo entonces, se nos revela como un caso particular de la función de la imago, que es establecer una relación del sujeto con su realidad; o, como se ha dicho, del Innenwelt (mundo interior) con el Umwelt (medio ambiente, naturaleza o mundo exterior) ( Lacan, 2009).

De está formulación sobre el estadio del espejo, Lacan toma las experiencias de Wallon sobre el reconocimiento de sí mismo del niño en el espejo (Rabinovich,1995). En este sentido Lacan argumenta: “Este acto, en efecto, lejos de agotarse, como en el mono, en el control, una vez adquirido, de la inanidad de la imagen, rebota en seguida en el niño en una serie de gestos en los que experimenta lúdicamente la relación de los movimientos asumidos de la imagen con su medio ambiente reflejado, y de ese complejo virtual con la realidad que reproduce, o sea con su propio cuerpo y con las personas, incluso con los objetos, que se encuentran junto a él" (Lacan, 2009, p.99). 
Sin embargo, Lacan además piensa a la imagen como simbólica, como determinada, como historizable y no como una mera percepción psicofisiológica. Al pensarla de este modo le permite a Lacan dar una nueva vuelta de tuerca sobre lo imaginario, a partir de su teoría sobre lo simbólico (Rabinovich,1995), que enfoca lo simbólico en el sentido de la lingüística, de la historia cultural y de la determinación social.

En 1953 cuando Lacan eleva el concepto de lo real al estatus de una categoría fundamental, la convierte en uno de las tres órdenes básicas de su metapsicología, señalando que un rasgo que delimita lo real de lo simbólico y de lo imaginario, no solo es que supone algo opuesto a lo imaginario, sino también algo situado más allá de lo simbólico: es el cuerpo inaccesible para el sujeto. En lo real no se da presencia o ausencia, pues aquí nada puede aparecer o desaparecer. Además, mientras lo simbólico es un conjunto de elementos discretos diferenciados, llamados significantes, lo real es indiferenciado, carece de fisuras. Es lo simbólico lo que puede introducir un corte en él (en lo real), cuando tiene lugar el proceso de significación de las cosas, siendo justamente lo real lo que resiste a la simbolización, lo que subsiste a ésta, convirtiéndose en lo imposible, lo inalcanzable, lo inimaginable, lo no simbolizable, todo lo cual da a lo real su esencial calidad de traumático (Sánchez et al., 2006).

Por tanto, la cura psicoanalítica sería, a partir de esos momentos, un diálogo que permite la reinclusión de lo imaginario en un adecuado registro simbólico, poniendo al analizante en condiciones de reconocer qué había construido su ser como una obra imaginaria (Sánchez et al., 2006). Sin embargo, el imaginario es simbólico (contienen significantes), historizable (analizable en el tiempo) y no una mera percepción psicofisiológica (imagen mental) o una simple representación estática y analítica, que no deja de ser imagen mental. Por eso es interesante revisar a Lacan para el tema de los imaginarios, primero por su dimensión simbólica, que suministra significantes y significados y a posteriori porque la imagen no es examinada como mera representación espontánea creada desde la imaginación. De ahí la importancia que representó Lacan en las Ciencias Sociales y en las Humanidades en general, debido a que fue un referente para la Escuela Postestructuralista.

Otra vertiente desde donde se analizan los imaginarios es el enfoque historiográfico y antropológico, que enmarca al imaginario como lo que esta instituido social e históricamente, pero además se objetiva en determinados elementos estáticos y, sobre todo, tangibles como textos, fotografías, utensilios, objetos, monumentos, por mencionar algunos. Entre sus representantes se ubica Cornelius Castoriadis, Jacques LeGoff, Gilbert Durand y su alumno Michel Maffesoli.

Desde Cornelius Castoriadis, por ejemplo, se argumenta que, para que se dé una significación social imaginaria, son necesarios unos significantes colectivamente disponibles, pero sobre todo unos significados que no existen del modo en el que existen los significados individuales (como percibidos, pensados o imaginados por tal sujeto). Los imaginarios instituidos o sociales, dan la funcionalidad a cada sistema institucional, tienen una orientación específica, sobredeterminan la elección y las conexiones de las redes simbólicas, son creación de cada época histórica, su manera singular de vivir, de ver y de hacer su propia existencia, su mundo y sus propias relaciones (Castoriadis, 2013). En otros términos, el papel del imaginario es el de instituir una determinada sociedad.

De ahí que es importante retomar algunos postulados desde Catoriadis para dar cuenta de los imaginarios impuestos verticalmente desde el capitalismo-neoliberalismo en las comunidades indígenas, donde se implementaron una serie de actividades económicas específicas de una sociedad capitalista -gobernada por hombres blancos-, que explotan la naturaleza y los bienes culturales, con el único objetivo de acumular más capital. Esta explotación genera antagonismos y prácticas incompatibles con la sociedad orgánica de estos pueblos originarios, lo que posibilita modificaciones, violencia y contradicciones en los imaginarios de estas comunidades indígenas. Por tanto, es necesario retomar a Castoriadis, ya que él delineó a los imaginarios, desde lo que nombra como lo social instituido, es decir desde la historia hecha. Ello presenta algunos problemas, en tanto si los imaginarios son analizados en ausencia de los sujetos que los construyen, es fácil caer en la cosificación de los mismos, de ahí la importancia de los enfoques centrados en lo biográfico, en el sujeto de los procesos culturales, como es el caso de un análisis trabajado desde la fenomenología.

Otro historiador es Jacques LeGoff, quien abogaba por analizar los imaginarios particularmente desde una historia material. Este enfoque demuestra que 1) los imaginarios sociales tienen una materialidad tangible en los documentos y monumentos erigidos por las sociedades. Por tanto, pueden ser objeto de análisis como evidencia empírica. 2) Los imaginarios sociales son históricamente reconocibles y constituyen fuente para la comprensión de los esquemas interpretativos de los grupos sociales. 3) El historiador recurre a distintas fuentes como el mito, la literatura, la escultura, arquitectura y otras tantas prácticas sociales, que revelan un simbolismo y un sentido que 
puede ser descifrado históricamente, dando claves sobre los distintos aspectos de la vida cotidiana, que bajo otros métodos sería imposible captar (Cegarra, 2012).

Con LeGoff, los imaginarios se encarnan en formas materiales (documentos, monumentos, fotografías, etc) y por ello su postura es más adecuada para analizar los imaginarios por ejemplo turísticos, que se impusieron en una determinada época, utilizando elementos publicitarios como folletos, fotografías, postales, etc., o para dar cuenta efectivamente de la manera en cómo vivía cierta sociedad a través de sus escritos, monumentos, arquitectura, pintura, utensilios y otras formas tangibles que materializan las prácticas y creencias de un colectivo. Aunque claro, en este escenario siempre es posible o más sencillo, delimitar los imaginarios desde el sujeto-historiador que lee e interpreta estos materiales, que desde el propio colectivo que vivió los sucesos.

Otro caso notorio pero desde la antropología es Gilbert Durand, quién en su obra Las estructuras antropológicas del imaginario desarrolla con gran lucidez la idea pragmática según la cual los signos, independientemente de su poder de significar, informar o evocar, también tienen la capacidad de ligar y desligar a los hombres (Durand, 2004). La obra es una vasta exploración teórica y polémica en torno a la constancia de las imágenes arquetípicas, que orientan a las formaciones civilizatorias y que pueden ser investigadas a través de la composición histórica de los regímenes simbólicos, que gobiernan la imaginación (Solares, 2011). El imaginario entonces representa para Durand, el conjunto de imágenes interrelacionadas que constituyen el pensamiento del hombre, así como el denominador central en el que se acumulan los otros mecanismos de dicho pensamiento (Durand, 2004). En este sentido, Durand también se dedicó como menciona Debarbieux (2012), a la búsqueda de los fundamentos antropológicos de las recurrencias de nuestros imaginarios, fundamentos que se ubican en la morfología y las experiencias corporales.

Y es desde está antropología simbólica que se crítica la fallida aproximación fenomenológica, semiológica y sociológica a los imaginarios -a partir de una revalorización de la imagen simbólica como fuente de conocimiento, Durand enfrenta a las hermenéuticas reductivas de la cultura, a la psicología freudiana, a la sociología y a la lingüística - abogando por el camino de la antropología para su verdadera comprensión (Solares,2011). Debido a que la considera un "trayecto antropológico, o sea, el incesante intercambio que existe en el nivel de lo imaginario entre pulsaciones subjetivas y asimiladoras y las intimaciones objetivas que emanan del medio cósmico y social" (Durand, 2004, p. 43). Es decir, el imaginario parte de los subjetivo pero finaliza y se mezcla con lo material, con lo objetivado de cada sociedad.

Por su parte Paul Ricoeur, Rachid Amirou, Juan Luis Pintos, Armando Silva, Susana Gastal,Daniel Hiernaux y Manuel Antonio Baeza, desde las ciencias sociales en general, exponen sus respectivas posturas respecto a los imaginarios.

Paul Ricoeur por ejemplo, desde la fenomenología y la hermenéutica, analizó no el imaginario como tal, sino la imaginación en su vertiente funcional como menciona Lythgoe (2014): "La problemática de la imaginación impregna la mayor parte de las investigaciones de Ricoeur después de la década de los sesenta" (Revault d'Allones 1997,p.13 en Lythgoe, 2014, p.73). Mientras sus trabajos tempranos -en particular Libertad y naturaleza (1950)se ajustaban a las convenciones descriptivas de la fenomenología eidética, la publicación de La simbología del mal en 1960 introdujo un modelo hermenéutico de análisis, "que abrió la posibilidad de una nueva apreciación del funcionamiento lingüístico de la imaginación” (Kearney, 1998,p.134-135 en Lythgoe, 2014,p. 73). Pese a la originalidad y a la extensión de la problemática de la imaginación, "en el trabajo publicado de Ricoeur encontramos sólo referencias dispersas sobre este tópico y ningún desarrollo amplio sobre este tema aparentemente tan central para su pensamiento" (Taylor, 2006,p. 93 en Lythgoe, 2014,p. 74). Una posible explicación de esta ausencia podría ser que al filósofo le interesaba la función de la imaginación y no sus contenidos, por lo que su tratamiento se subordinó a otras temáticas afectadas por esa funcionalidad de la imaginación (Lythgoe, 2014).

Es por lo anterior, que a pesar de la importancia de la obra de Ricoeur, la categoría sobre imaginación no es útil para construir, para analizar imaginarios sociales, porque estos no son totalmente imaginación, son una red de habitualidades compuestas de la sedimentación de sentido, donde la imaginación solo es una elemento que facilita evocar plenamente la cosa u objeto material.

En una línea similar Manuel Antonio Baeza en su obra Imaginarios sociales. Apuntes para la discusión teórica y metodológica, desarrolla ocho argumentos básicos para la construcción de una teoría fenomenológica de los imaginarios sociales, donde refiere a los imaginarios sociales como "múltiples y variadas construcciones mentales (ideaciones) socialmente compartidas de significancia práctica del mundo, en sentido amplio, destinadas al otorgamiento de sentido existencial” (2003 ,p. 20). 
Como vemos si bien con Paul Ricoeur y Baeza nos acercamos a la fenomenología -nuestro principal punto de interés para abordar los imaginarios sociales-, este último solo desarrolla sus investigaciones desde los temas de la sociología (Baeza y Silva, 2009; Aravena y Baeza, 2015) y no parte estrictamente desde la filosofía para llegar a la fenomenología trascendental -es decir a la obra de Edmund Husserl- y de ahí a las habitualidades y a los imaginarios, que es el camino vía el cual se intenta construir un primer acercamiento a una propuesta teóricometodológica, sobre imaginarios sociales en comunidades indígenas, insertas en dinámicas turísticas.

Por ello solo se mencionará a este autor, para mostrar que si hay investigaciones en América Latina para trabajar los imaginarios desde la fenomenología, pero que no se encontró una propuesta desarrollada a profundidad para analizar los imaginarios sociales desde la fenomenología de Husserl, que centra al sujeto de los procesos culturales, socio-económicos y políticos.

En este marco otro autor, que se interesó por los imaginarios, aunque no desde la fenomenología o la hermenéutica, sino más bien desde la sociología y el turismo, fue Rachid Amirou, quién se dio a conocer a través de su sociología del turismo, el patrimonio cultural y los imaginarios. Amirou dedicó un gran esfuerzo a explicar la idea de un paraíso turístico, "la imagen secular del paraíso, para Amirou, coincide con la de un espacio mental inicial, protector, en el sentido de maternal. Así analiza la noción de encanto, abusada a través de la promoción turística, como parte también de este universo cultural simbólico del imaginario turístico edénico, como herramienta para potenciar intimidad, sencillez, nostalgia y proxémica" (Días et al., 2011, p.7) y ello lo explica en su artículo sobre Tourisme et postmodernité. Les métamorphoses de l'authenticité (2007b), al argumentar que el turista posmoderno no busca lo auténtico per se, sino su versión suave, hecha por la industria del ocio. Así este turista se satisface con un simulacro de realidad o autenticidad, es decir con un área de juego,donde aparentemente existe una ausencia del conflicto.

En este sentido, Amirou aporta una mirada crítica para pensar al turista en su no conexión con la comunidad receptora, con esa otredad marginada, donde el turista constantemente intenta escapar de lo real, sus conflictos y perversiones, a través de varios mecanismo como el área de juego (el imaginario de la isla, de Bachelard, como un espacio de felicidad y seguridad) o la emisión de postales, que como bien menciona en su artículo De l'imagerie populaire à l'Imaginaire touristique (2002a), una postal es una imagen simplificadora de los destinos turísticos, la postal es, en cierto modo, la quintaesencia del imaginario turístico. Narra un sueño realizado por el remitente pero no deja de ser una imagen "recreada", que inventa lugares o paisajes idílicos.Por tanto estas categorías de Amirou, serían muy útiles para completar un estudio sobre imaginarios sociales intersubjetivos en los pueblos indígenas versus los imaginarios turísticos, desde ese turista que consume indiferencia.Sin embargo, nuestro estudio por el momento solo intenta demarcar los imaginarios en las comunidades indígenas, frente al turismo rural.

Por otra parte Juan Luis Pintos, define a los imaginarios sociales como esquemas construidos socialmente, no construidos por los sujetos sino por las estructuras y sistemas en que esos sujetos habitan- que orientan la percepción - no nuestra acción ni nuestro pensamiento. Así los imaginarios hacen posible la intervención en lo que en diferentes sistemas sociales se tenga como realidad (Pintos, 2014).

En consecuencia si se analiza esta definición de Pintos, desde las posturas y disciplinas vía la cuales se pretende trabajar los imaginarios -fenomenología de Husserl y sociología desde Castoriadis-, la primera observación radica en que Pintos, es más cercano a la visión que Castoriadis tiene sobre imaginarios, al mencionar que los imaginarios son edificaciones de las estructuras y los sistemas y no construidos desde los sujetos, sin embargo todo imaginario social ahora institucionalizado- de acuerdo con Castoriadis -se fundó en el conjunto de sujetos y agrega Pintos que además los imaginarios orientan la percepción, más no la acción ni el pensamiento o la integración ideológica de un grupo. Pero la percepción es parte del pensamiento, es gracias a la percepción, si esta se entiende como experiencia sensible, que se significa el mundo y lo que hay en el. Y esta significación del mundo nos permite mediar nuestras acciones. Finalmente las creencias de un colectivo, son también una forma de imaginarios sociales, contrario a lo que piensa Pintos.

Armando Silva (2013), por su parte analiza los imaginarios pero no solo como representaciones en abstracto y de naturaleza mental, sino en su función de encarnarse e incorporarse en objetos ciudadanos que encontramos a la luz pública y de los cuales podemos deducir sentimientos sociales como miedo, amor, rabia o ilusiones, estos tantos sentimientos citadinos son archivables a manera de escritos, imágenes, sonidos, producciones de arte o textos, donde lo imaginario impone sus valor dominante sobre el mismo objeto. "Por eso, entonces, entendemos que todo objeto urbano no solo tiene su función de utilidad cierta, sino que el mismo puede sobrecargarse de una mayor valoración imaginaria que lo dota de otra sustancia representacional" (Silva, 2013,p. 22). 
Los imaginarios son así: verdades sociales no científicas, de ahí su cercanía con la dimensión estética de cada colectividad (Silva, 2013). Sin embargo, Silva trabaja imaginarios en la urbe, en el espacio citadino (2004 y 2013) y es en el y a través de el, que rastrea los imaginarios que los sujetos sienten (miedo, amor, rabia, inseguridad, etc.) y que plasman en el arte, el graffiti, las fotografías, los textos entre otros, sin embargo el autor no analiza los espacios rurales y menos los indígenas pero además su enfoque es más bien para hacer cuantitativo y generalizable el imaginario en una determinado barrio, municipio o ciudad -ocasionando una verdadera reducción narrativa-, dejando del lado las particularidades dadas por las especificidades de cada imaginario local y único, así como la complejidad del imaginario social en los colectivo. Por tal motivo, no es posible retomarlo para esta primer acercamiento a una propuesta sobre imaginarios sociales, sin embargo, se reconoce que es un referente en la investigación sobre imaginarios urbanos, especialmente en Colombia.

En esta senda sobre la espacialidad pero especialmente desde el turismo, encontramos además a Daniel Hiernaux (2007), quién trabaja no solo los imaginarios en la geografía humana sino también los imaginarios aplicados al turismo (Hiernaux, 2002; Hiernaux y González, 2015) pero desde la perspectiva del turista, él argumenta que el imaginario funciona sobre la base de re-presentaciones que son una forma de traducir en una imagen mental, una realidad material o bien una concepción. En otros términos, en la formación del imaginario se ubica nuestra percepción transformada en representaciones a través de la imaginación, proceso por el cual la representación sufre una transformación simbólica. Empero su perspectiva tampoco es compatible con los intereses u objetivos de este artículo, debido a que lo que interesa para este análisis es generar una primera propuesta o acercamiento para demarcar los imaginarios de la comunidad receptora -sujetos originarios del territorios que reciben y atiende a los turistas- y no seguir reproduciendo estudios sobre la percepción del turista.

Así una autora más que trabaja imaginarios turísticos es Susana Gastal (2005), ella argumenta que la gente viaja; y entre los diferentes tipos de viajes se puede decir que hay una presencia común de imágenes e imaginería. Imágenes porque, antes de mudarse a un nuevo lugar, la gente ya habrá entrado en contacto visual con el destino, a través de fotos en periódicos, folletos, escenas de películas, páginas en internet, entre otros e imaginario porque las personas tendrán sentimientos que los llevarán a encontrar un lugar como romántico, peligroso, bello o civilizado. Así Gastal analiza la relación íntima que se crea entre turismo, imágenes e imaginario.

En este marco habría que prestar especial atención a estudios latinoamericanos sobre imaginarios del turismo, por tanto algunos autores que se nombran son Eloy Méndez (2013), Jesús Ángel Enríquez (2015; 2017), Rosa Vargas Ochoa (2015; 2017), Cristina León (2017), y Mario Alberto Velázquez (2013). Ellos discuten respecto a los imaginarios del patrimonio turístico, territorio, gentrificación. Y abordan problemáticas desde los pueblos mágicos, “los pueblos con encanto y los imaginarios y representaciones detrás de eso: la búsqueda del ocio, el regreso a la naturaleza,la búsqueda de lo colorido, lo folklórico, lo típico, el descubrimiento de los otros, las percepciones de los viajeros, en especial los jóvenes, junto con elementos profundos ligados a los imaginarios del orden, la higiene, la felicidad" (Girola y González, 2020, pp.40-41).

A la par habría que rescatar una de las redes sobre investigación en imaginarios sociales y turismo más reconocidas en América Latina: la Red Iberoamericana de Investigación en Imaginarios y Representaciones (RIIR), donde destacan las publicaciones de: Paula Vera y Ariel Gravano de Argentina; Danielle Perin Rocha Pitta, en Brasil; María Lily Maric en Bolivia; Manuel Antonio Baeza Rodríguez, Oscar Basulto Gallegos (2020) y Andrea Aravena Reyes (2019) en Chile; Armando Silva, Cristhian Uribe Mendoza y Felipe Aliaga Sáez en Colombia; René Villaboy Zaldivar, en Cuba; Diego Apolo Buenaño, en Ecuador; Enrique Carretero Pasin, José Angel Bergua Amores, Javier Diz Casal, en España; Francesca Randazzo Eisemann, en Honduras; Lidia Graciela Girola Molina (2020), Josafat Morales Rubio y Laura S. Zamudio Vega (2012), en México; Carlos Vera Abed, en Paraguay; Osbaldo Turpo Gebera, en Perú; Manuel Alves de Oliveira, en Portugal; Fernando Andacht, en Uruguay; Luz Gisella Pargas López en Venezuela y Michel Maffesoli y Apolline Torregrosa, en Francia.

Como se observa, los enfoques vía los cuales se analizan los imaginarios poseen ciertos matices que permiten dilucidar diferencias, mientras unos determinan los imaginarios como imágenes mentales, otros argumentan que son objetivables a través de elementos tangibles, estáticos e institucionalizados. Sin embargo, se debe puntualizar que los imaginarios sociales son también concepciones dinámicas del mundo y de la realidad que forma el entorno histórico de sujetos concretos. En este sentido, la definición de los imaginarios sociales sigue históricamente las tres direcciones antes mencionadas: ciencias cognitivas; historiográfico y antropológico, y ciencias sociales en general. 


\section{INVOCANDO OTRAS POSIBILIDADES PARA EL ESTUDIO DE LOS IMAGINARIOS}

Los imaginarios se ha abordado particularmente en las direcciones antes mencionadas, pero en este momento quizá ninguna permite abordar adecuadamente los fenómenos contemporáneos, concretamente sobre turismo rural en comunidades indígenas. Es en función de esto que se invocan otras posibilidades.

Por ello es pertinente exponer de manera muy general, la postura bajo la cuál se propone trabajar un primer acercamiento hacia los imaginarios sociales, desde las comunidades indígenas, inmersas en dinámicas turísticas. En este sentido se antoja obvio preguntar ¿qué se entiende concretamente como imaginario social? ¿cuáles son los elementos que lo componen? ¿qué se necesita revisar para dar cuenta de ellos? ¿qué hay detrás del imaginario social que permite moldear constantemente las relaciones con el otro, y con el mundo de la vida cotidiana? ¿cuáles son los elementos que entretejen, conforman o construyen la trama de sentido de los imaginarios? y ¿en qué medida el imaginario determina las prácticas en colectivo?

En respuesta a estas interrogantes se menciona que se analizará la construcción dinámica y, a veces, antagónica o contradictoria de los imaginarios desde la fenomenología, entendida esta como el análisis de las experiencias intersubjetivas, y los imaginarios sociales en tanto redes de habitualidades, mismas que se construyen en la sedimentación de sentido. El sentido es la parte nodal en los imaginarios, ya que es a través del mismo que se habita y se comprende el mundo de la vida, es el que posibilita interactuar con la alteridad y a través del cual se pertenece y se construye comunidad. Y es por eso que los imaginarios permiten construir identidad con un territorio, son mecanismos de resistencia contra el olvido, contra el tiempo y también contra la imposición de prácticas coloniales o de dominación, aunque pueden ser lo contrario, es decir mecanismos que impongan formas capitalistas y de dominación.

El imaginario social permite dar sentido, ordenar las evocaciones de sentido, significar el mundo habitado, al cohabitar con el otro, donde aparecen manifestaciones, prácticas y modos particulares de vivir desde lo común, o lo individual e instrumental.

El imaginario social, es entonces y retomando la metáfora de Durand (1994) pero desde la fenomenología: Un museo de experiencias pasadas (en clave asociación), presentes y por producir (en clave motivación). 0 desde Alicia Lindón (2012), un patrimonio pero que rebasa, que se ubica mas allá de un simple conjunto de ideas e imágenes, más bien sí es un patrimonio, pero de sentido. O puede ser que los imaginarios se comprendan desde la musicalidad, entendida desde Custodero (2006), como la capacidad de otorgar sentido no a lo acústico o la rítmico sino a la experiencia, el imaginario se presenta entonces como la musicalidad de la experiencia. Pero los imaginarios también son herramientas estéticas de sentido, para pensar las formas bajo las cuales no solo asumimos sino intervenimos el mundo.

Empero, no todos los imaginarios están fabricados con la misma madera como bien argumenta Claval (2012), en las sociedades tradicionales o pueblos originarios, las preguntas que se plantean los sujetos son distintas. La primera diferencia evidentemente es la que Paul Gauguin utilizó como título en una de sus obras en el Museo de Bellas Artes de Boston: ¿De dónde venimos? ¿Quiénes somos? ¿A dónde vamos? y agrega Claval (2012) ¿Por qué somos tan frágiles? ¿Por qué nuestra existencia siempre esta amenazada por la enfermedad, por la maldad de los seres humanos -y se agregaría- o violentada por la acumulación del capital, que deviene en despojo de los bienes comunes, en la disciplina del dinero o en la imposición de actividades turísticas en el medio rural?

Con esta idea de pueblos originarios, únicos y no hegemónicos, la construcción desde lo social deberá ir ligada a la construcción de espacio-temporalidades específicas con características particulares, pero no por ello se evocan imaginarios estáticos, algo muy característico en Castoriadis, sino más bien cada sociedad se dota de imaginarios que no solo permiten significar sino que ese sentido específico admite, genera o guía acciones y prácticas particulares e internas. Por ello, estos imaginarios son también una forma de mediar la generación de sentidos con las acciones o prácticas. Es por medio de esa mediación que los imaginarios se movilizan en la praxis, pero su sentido nunca será independiente de las intersubjetividades que la generan. Es decir, los imaginarios sociales, son también manifestaciones para abordar la subjetividad social.

En este marco, Berdoulay (2012) argumenta que los imaginarios sociales permiten maniobrar y accionar la posibilidad de distanciarse de los significados institucionalizados por ciertos poderes, en este caso los imaginarios más bien instituidos. En este sentido Lindón (2012) agrega, existen los imaginarios en términos del engaño, refiriéndose también a que se hace uso de los imaginarios para legitimar ciertos procesos históricos, sobre todo diversas formas de colonización y con ello también de cientificidad. Esto abre la posibilidad de articular los 
imaginarios con el pensamiento crítico y postcolonial, que destaca la necesidad de deconstruir los saberes o abrir las categorías que legitiman ciertas visiones hegemónicas y dominantes para la ciencia, la economía, la salud, por mencionar algunos. De ahí la pertinencia de trabajar los imaginarios sociales desde las evocaciones y manifestaciones de las comunidades originarias, en ese marco desde las subjetividades subalternas.

En consecuencia Lindón (2012), además menciona, ya no sólo basta con analizar los imaginarios anclados específicamente en el nivel de los horizontes de sentido, o la trama de significados, porque ello deja una asignatura pendiente acerca de las formas que (1) emergen, (2) se resemantizan y (3) se aplican los imaginarios, en situaciones concretas de la cotidianidad de los diversos sujetos-habitantes.

Lo anterior permite marcar y recorrer senderos poco transitados o apenas esbozados. En el caso, por ejemplo, de (1) la emergencia ¿de cómo emergen los imaginarios? la mirada y la base teórica de la fenomenología resuelve esta interrogante, vía las habitualidades activas y pasivas, donde las activas también permiten dar respuesta a la (2) resemantización (resignificación) de los imaginarios que comenta Lindón.

Y para la praxis de los imaginarios y cómo la praxis cotidiana altera, modifica y configura imaginarios, una herramienta muy útil para dar cuenta de ello, es a través de las categorías aportadas por la teoría crítica o el marxismo abierto. Por ejemplo desde Ana Dinerstein (2017), se piensa en cómo ciertas prácticas concretas pueden producir una ruptura en los imaginarios dominantes del capitalismo patriarcal y colonial, a través de utopías concretas: se niega dicho mundo a través de afirmar la alternativa por medio de la praxis y una crítica experimentada, vivida. O mediante las contradicciones (antagonismo), al navegar la contradicción entre la necesidad de reproducirnos a través del dinero y eliminar el dinero como forma de reproducción, debemos navegar en una serie de contradicciones experimentadas con, contra o más allá del Estado, la ley, el dinero, es decir con, contra y más allá - como menciona Holloway (2015)- de las mediaciones de la lucha, por formas alternativas de reproducción social. Estas mediaciones: el Estado, la ley, el Capital, son constitutivas de la subjetividad de lucha y no contextuales.

En este marco, dada la existencia de imaginarios que anteceden, en esta condición de sedimentación de sentido (históricos y socioculturales), y dada la existencia de imaginarios que son impuestos (instituidos), se da una disputa y una transformación constante de los mismos.

Por lo anterior, en un primer intento de esbozar una propuesta sobre imaginarios sociales para analizar la realidad de las comunidades indígenas frente al turismo rural y en aras de cubrir dicho vacío en los estudios turísticos, se presenta un diagrama (ver tabla 1), que es un primer acercamiento hacia las epistemologías de los imaginarios sociales retomando conceptos centrales de Edmund Husserl, como las habitualidades para llegar a los imaginarios intersubjetivos, así como lo social instituido de Cornelius Castoriadis, y otras categorías desde autores que trabajan teoría crítica y marxismo, con el fin de dirigirlos al análisis de las experiencias de comunidades originarias frente al turismo rural-indígena.

\subsection{Propuesta sobre imaginarios intersubjetivos}

El mundo es el horizonte universal donde existimos con los otros y en esta co-existencia el mundo es para nosotros consciente existente-viviente. A través de la intersubjetividad se constituye ese mundo como horizonte de una experiencia pre-científica o pre-teórica, o lo que es lo mismo, la subjetividad constituye, en la comunitarización intencional, la efectuación de la validez del horizonte experiencial del mundo. Esa validez originaria y vivenciada sobre el horizonte experiencial de las subjetividades en relación, da lugar a la unidad del mundo (Osorio, 2020).

Por tanto en el mundo de la vida existen sujetos y cada uno posee experiencia originaria.Esta experiencia originaria si se piensa como una suerte de edificio con diferentes niveles: el esqueleto que lo sostienen son las habitualidades-pasivas y activas-; el sótano es la conciencia originaria, donde se ubica la experiencia sensible (percepción sensible). Así las habitualidades se conciben como:

El resultado de una génesis activa que pasa o ha pasado en el ámbito de la pasividad. Por eso podemos distinguir en Husserl dos sentidos de pasividad, primaria (la de las asociaciones de la esfera primitiva, sensible de la experiencia) y secundaria, que sintetiza con base en actividades del yo previamente ejecutadas, que permiten la demarcación del "sentido" (histórico y cultural) de la experiencia. La capacidad de caminar, de hablar una lengua con naturalidad, de reconocer la disposición de una mesa y asumirla no sólo como mesa sino como "comedor" y actuar en consecuencia, es en todos los casos el correlato de habitualidades y su sentido se formó gracias al sedimento de una génesis activa, que ahora se vive como pasividad con respecto a las actividades del yo actual que las presupone (Quepons en Osorio, 2020,p. 25). 
En consecuencia, cada sujeto es portador de una historicidad individual cimentada a través de sus habitualidades. Una habitualidad es social a través de la empatía con el otro, es decir desde la intersubjetividad.

En este sentido no es que exista una colección de subjetividades sociales, sino que se reúnen para formar una subjetividad social más o menos organizada, que tiene su enfrentante común en un mundo circundante o mundo externo, en un mundo que es para todos (Husserl,2005). Es decir, en un determinado colectivo existe una unidad de sentido intersubjetivamente constituida, o si se prefiere de habitualidades sociales que, efectivamente, se gestó con la agrupación de subjetividades-individuales. Para el caso se puede mencionar que en comunidades indígenas, el sujeto-social nace en lo pre-dado de las construcciones sociales del mundo de la vida, pero estas construcciones se modifican en el tiempo y con la interacción de subjetividades, donde:

Al interactuar en ese mundo, se unifica y por tanto se agrupa una determinada subjetividad social o intersubjetividad predominante, sin embargo está nunca es estática sino que se modifica constantemente con el devenir y las interacciones, de los sujetos que se relacionan, movidos por un campo de habitualidades tanto pasivas como activas (Osorio, 2020, p. 98).

Así las habitualidades son el resultado de la génesis pasiva y activa, que en su conjunto integran los imaginarios subjetivos, es decir desde el sujeto individual pero como sujeto social, como persona histórica. Las habitualidades, en la empatía con el otro, se constituyen como habitualidades sociales (ver tabla 1), suministro de los imaginarios intersubjetivos, categoría con la que ahora es posible analizar los imaginarios sociales.

En consecuencia, si bien ya podemos comprender y demarcar los imaginarios desde la intersubjetividad en las comunidades indígenas, es evidente que dicha intersubjetividad esta atravesada y violentada por otros imaginarios, más bien dominantes, capitalistas e institucionalizados, por eso la pertinencia de contrastar estos imaginarios de la intersubjetividad versus los instituidos del capitalismo, vía la implementación de actividades de turismo rural en los pueblos originarios.

Tabla 1 - Esquema de imaginarios intersubjetivos

\section{Imaginario intersubjetivo}

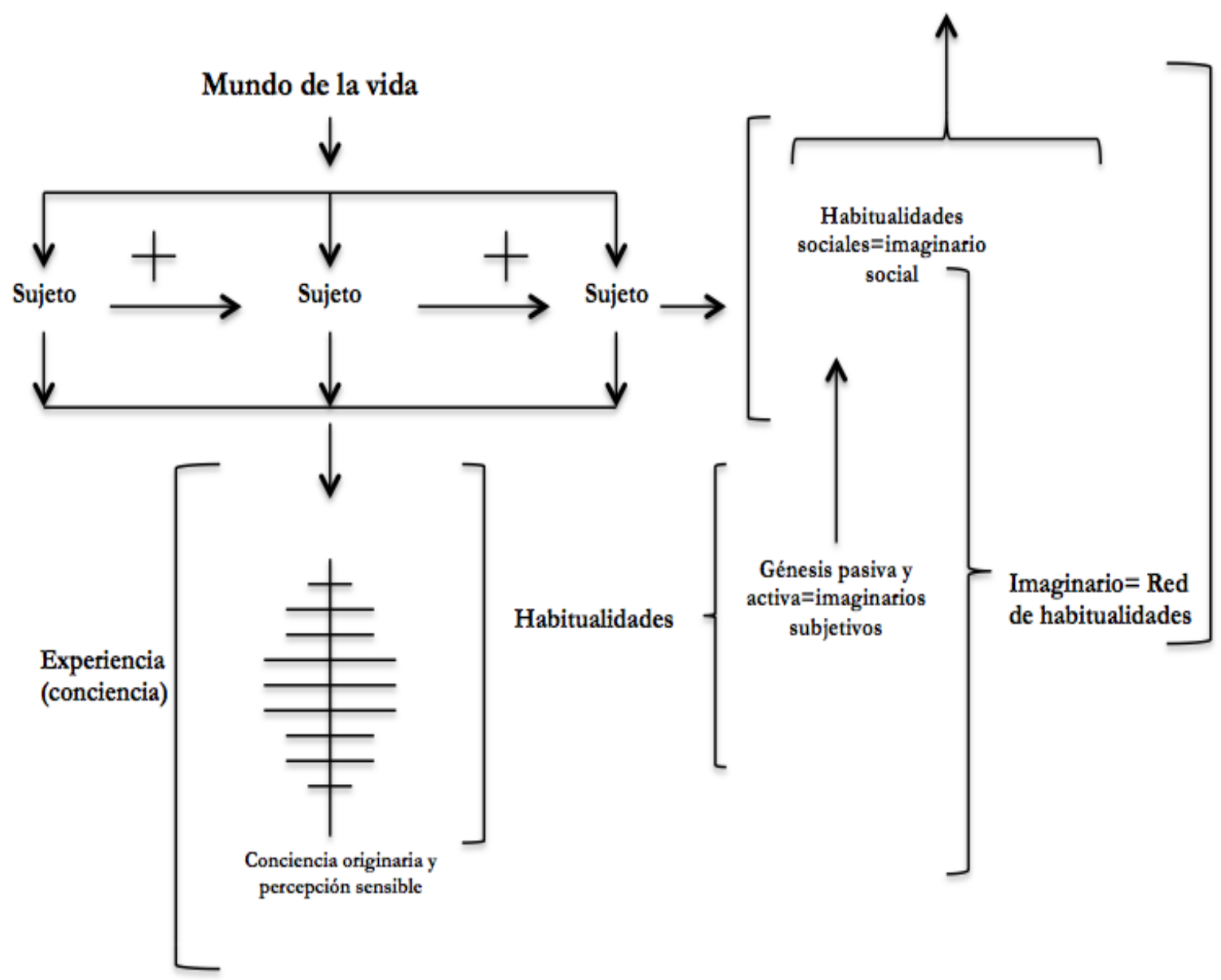

Fuente: Elaboración propia con base en Husserl (1962; 1979; 1980; 2005; 2008) y Osorio (2020). 


\subsection{Propuesta sobre imaginarios instituidos}

Lo imaginario social o lo social instituido es en y por la posición-creación de significaciones imaginarias sociales y de la institución; de la institución como presentificación de significaciones, y de estas significaciones como instituidas. Asimismo, Castoriadis hace algunas precisiones y por ello argumenta:

Elegí el término significaciones porque me parece el menos inepto para expresar lo que quiero. Pero no debe ser tomado de ningún modo en un sentido mentalista. Las significaciones imaginarias sociales crean un mundo propio para la sociedad considerada, son en realidad ese mundo: conforman la psique de los individuos. Crean así una representación del mundo, incluida la sociedad misma y su lugar en ese mundo (Castoriadis, 1997, p. 9).

Los imaginarios sociales instituidos, por tanto, son conceptualizados de esta manera, no solo porque representan las significaciones propias de una determinada sociedad en un momento histórico específico, sino porque además tienen un significante instituido como validado y reproducido -ello no necesariamente indica que es aceptado desde la docilidad-, y además es instituido por representar una institución específica, por ejemplo el modelo económico dominante (capitalismo-neoliberalismo) o el Estado Neoliberal.

Estas dos instituciones representan, expresan y reproducen una serie de imaginarios dominantes y coloniales que permiten el control sobre los sujetos o comunidades menos favorecidas. Por ello, Castoriadis (2013) menciona que las instituciones pueden ser, y son efectivamente, alienantes en su contenido específico. Lo son en la medida que expresan y sancionan una estructura de clase, más generalmente una división antagónica de la sociedad.

Desde esta óptica, los imaginarios instituidos del turismo rural en el neoliberalismo -entendidos como significaciones imaginarias sociales y de la institución- muestran diversidad de matices, ya que son impuestos por instituciones internacionales, nacionales y estatales, encasillados en: el libre mercado, crecimiento económico, terciarización del campo y en el campesino o indígena empresario. Por ello la pertinencia de analizarlos desde la postura de Cornelius Castoriadis pero, además, desarrollar una propuesta crítica para revisitar los imaginarios instituidos (historia hecha) desde la teoría crítica ( ver tabla 2).

Tabla 2 - Imaginarios intersubjetivos e instituidos desde la teoría crítica

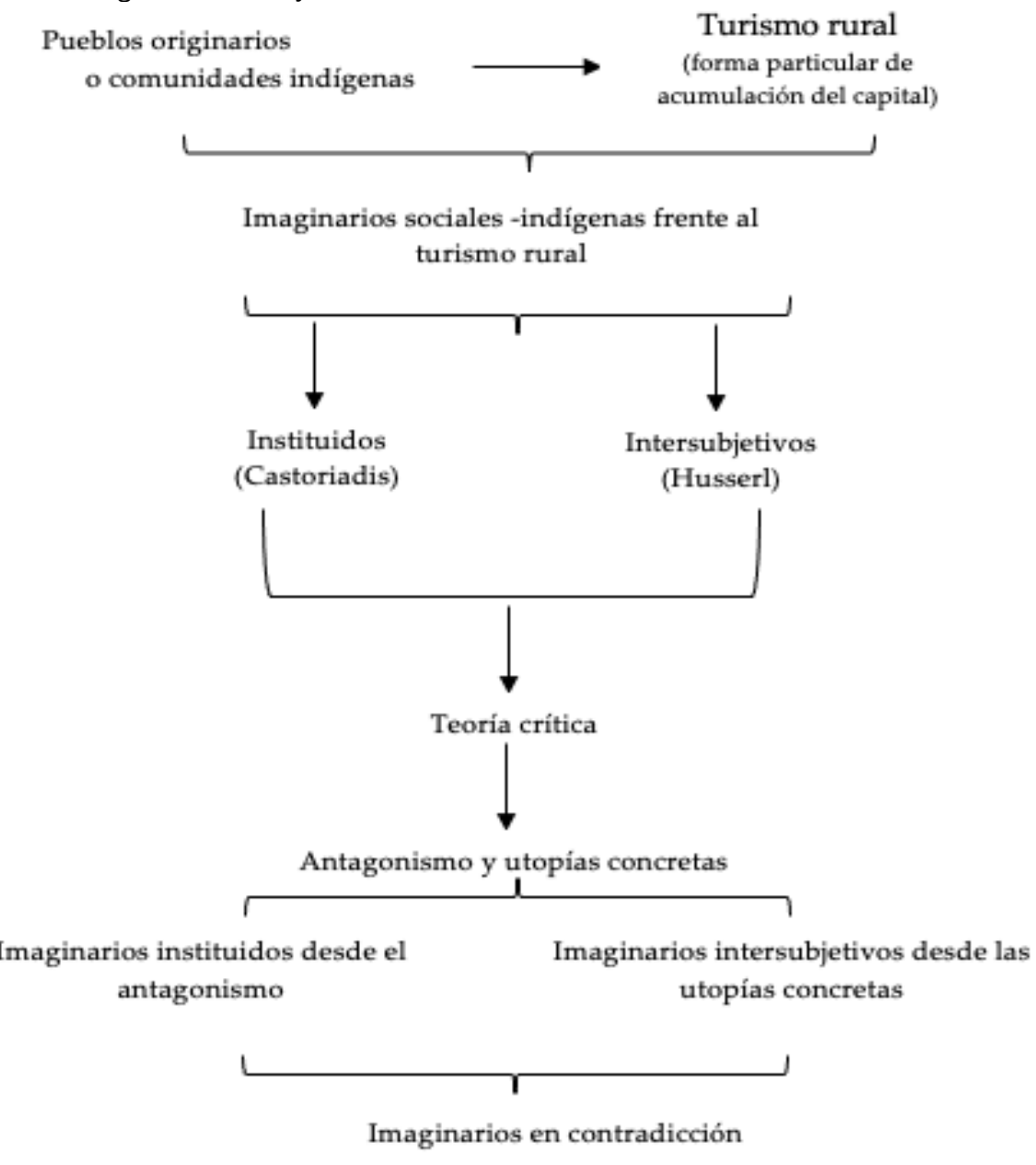

Fuente: Elaboración propia, 2020. 
Como se observa hay una propuesta propia, que se trabaja con categorías principales desde la fenomenología de Husserl,las habitualidades y el mundo de la vida, esto se hace para construir un puente hacia los imaginarios, ya que estrictamente Edmund Husserl nunca trabajó imaginarios sociales. En el caso de Castoriadis, se retoman solo los imaginarios instituidos, pero se revisitan bajo la lupa del pensamiento crítico y, finalmente, sí desde la teoría crítica no hay un mayor aporte, que el proponer imaginarios intersubjetivos e instituidos analizados desde una postura crítica, utilizando categorías centrales como antagonismo (contradicción) y utopías concretas.

Entendiendo las utopías concretas desde Ana Dinerstein (2017), como formas alternativas de reproducción social, que afirman al negar, puesto que no suponen una acción positiva sino afirmativa. Mientras la primera acepta el mundo tal cual es, buscando acomodarse, la segunda niega dicho mundo a través de afirmar la alternativa, por medio de una crítica experimentada, vivida.

En este tenor, la utopía concreta desafía los parámetros de legibilidad de la realidad dada, convirtiéndose en una forma compleja de la resistencia que -simultáneamente- niega, crea, entra en contradicción en, contra, y más allá del Estado, la ley, el Capital (Dinerstein, 2017), para producir un excedente intraducible en el lenguaje capitalista, patriarcal y colonial. En otras palabras esto se traduce en imaginarios instituidos versus imaginarios intersubjetivos, desde las utopías concretas en las comunidades o pueblos indígenas.

Sin embargo, de qué forma es posible demarcar en la praxis estos imaginarios instituidos e intersubjetivos, es decir ¿a través de qué esquemas metodológicos es posible reconocerlos y visibilizarlos? El siguiente apartado busca mostrar algunos acercamientos que permiten dar una respuesta tentativa a dicha interrogante, toda vez que el análisis de los imaginarios sociales es un campo relativamente fértil y más aún sus métodos e instrumentos metodológicos.

\section{METODOLOGÍAS PARA LA DEMARCACIÓN DE LOS IMAGINARIOS}

Antes de presentar el enfoque, método y texto con el cual se cree pertinente abordar los recortes empíricos de los imaginarios, es necesario mostrar para fines de reflexión y referencia, bajo qué enfoques y con qué herramientas algunos investigadores contemporáneos trabajaron el tema de los imaginarios. Por tanto, tenemos a: 1) Silva, A. (2004). Imaginarios urbanos: hacia el desarrollo del urbanismo desde los ciudadanos. Metodología. Colombia: Universidad Nacional de Colombia; 2) Colín Mar, I. (2014). Sociogénesis del conflicto: una interpretación desde el imaginario social y la tradición oral en la comunidad de Malinalco. México. Tesis de posgrado, UAEM y 3) Sollerio A. A. A y García, M. O (2020). La producción del espacio social en Playa del Carmen, Quintana Roo, México. Espacialidad, Socialidad e Historicidad. Revista Brasileira de Pesquisa em Turismo, São Paulo,14(2), p. 95-122. Cuyas técnicas de producción de datos se presentan en el siguiente cuadro:

Tabla 3 - Técnicas de producción de información

\begin{tabular}{|c|c|c|c|c|}
\hline Autor & Técnica & Descripción & Categorías & Observación \\
\hline $\begin{array}{l}\text { Armando } \\
\text { Silva }\end{array}$ & -Encuesta & $\begin{array}{l}\text { Las encuestas forman parte de las técnicas cuantita- } \\
\text { tivas para la recopilación de información, pues per- } \\
\text { mite tener una visión general de la opinión de una po- } \\
\text { blación respecto del fenómeno estudiado, al contar } \\
\text { con datos porcentuales establecidos mediante una } \\
\text { muestra representativa de la población a estudiar }\end{array}$ & $\begin{array}{l}\text {-Ciudad } \\
\text {-Calificaciones urbanas } \\
\text {-Escenarios urbanos } \\
\text {-Ciudadanos } \\
\text {-Temporalidades ciuda- } \\
\text { danas } \\
\text {-Marcas ciudadanas } \\
\text {-Rutinas ciudadanas } \\
\text {-Otredades } \\
\text {-Percepción desde los } \\
\text { otros }\end{array}$ & $\begin{array}{l}\text { Armando Silva retoma } \\
\text { para estas categorías a } \\
\text { Mariluz Restrepo (filó- } \\
\text { sofa), quién a su vez } \\
\text { construye con la se- } \\
\text { miótica de Charles Pei- } \\
\text { rce. }\end{array}$ \\
\hline
\end{tabular}

-Puntos de Los puntos de vista: "Son una serie de estrategias disvista cursivas por medio de las cuales los ciudadanos narran las historias de su ciudad, aun cuando tales relatos pueden, igualmente ser representados en imágenes visuales. Con esta categoría se propone salir del estudio de la imagen como acontecimiento gráfico y se dio la posibilidad de examinar la construcción de la imagen, bien deduciendo al destinatario previsto en cualquier imagen o, en otro caso, consultando directamente a los ciudadanos" (Silva, 2004,p.22). 
Tabla 3 - Técnicas de producción de información

\begin{tabular}{ll} 
Autor & Técnica \\
\hline Armando & -Croquis \\
Silva &
\end{tabular}

Tiempo y lugar de una imagen

-Emblema

-Un sondeo exkowski ploratorio al Muchnik azar.

-Entrevista en profundidad

-Entrevistas se miestructuradas

-Observación participante

-Análisis de contenido de un corpus de imágenes fotográficas y de video.

Andrea -Técnicas de Aranxa observación no Albarrán participante Sollerio y -Revisión de doMaribel cumentos de Osorio archivos

García -Encuesta y entrevistas a personas clave $\mathrm{y}$ residentes
Croquis: Se entiende por croquis sobre imaginarios de los ciudadanos, el reconocer las formas de la ciudad que habita en las mentes de los ciudadanos por segmentación e interiorización de sus espacios vividos y de su proyección grupal, según distintos "puntos de vista urbanos". Se refiere entonces a una temporalización de sus espacios vitales, a un tiempo recorrido, a un habitante-ciudadano (Silva, 2004, p.26).

Una foto se valora desde el instante en el que se toma.Técnica para capturar situaciones urbanas, tanto públicas como privadas. $Y$ ya sea porque se recoge de un periódico o revista que las ha captado y el investigador las recupera para su archivo de investigación (Silva, 2004).

Un emblema se define como una representación de alta concentración simbólica, desde un punto de vista urbano o por todo un conjunto ciudadano.Así, los emblemas pueden convertirse en estandartes ciudadanos para un determinado territorio y para un periodo de tiempo determinado. Un emblema actúa como icono de la cultura urbana y pasa a representar a una ciudad pensada desde sus urbanismos ciudadanos. Los emblemas consiguen y mantienen el poder de evocar a una ciudad y son tales tanto en sus valoraciones positivas como negativas.Por lo anterior los emblemas participan de la naturaleza estética de una ciudad.Son las figuras que más significativamente expresan y por eso representan su imagen pública (Silva, 2004, p.26).

Entrevista: a los agentes gestores y administradores de las políticas de consumo cultural en el Centro Histórico (INAH, INBA e instituciones privadas).

- Imágenes y visiones que se constru yen

-Percepción, concepción y vivencia de los actores que han configurado el destino, para reconocer las formas de apropiación y uso que produce el turismo.
Estudio desde la antropología hermenéutica, que ha desarrollado habilidades interpretati-vas para captar las significatividades diversas que habitan el espacio urbano. De allí la potencialidad de esta disciplina para comprender la complejidad de las metrópolis contemporáneas.

A través de la información obtenida, se identificó que el espacio de Playa del Carmen ha sido apropiado con fines de acumulación del capital, fragmentan-do a la ciudad y creando fronteras de clase, tanto simbólicas como físicas.

Fuente: Elaboración propia con base en Silva (2004), Colín (2014) y Albarrán y Osorio (2020). 
Asimismo agregar que también es posible analizar los imaginarios sociales, desde las herramientas que brinda la geografía humana, entre ellas se ubica: la técnica del trabajo experiencial (involucrarse en los paisajes complejos de los mundos experienciales de las personas) (Rowles, 1978); narrativas de vida espaciales (Lindón, 2012) y mundo de la vida cotidiana; mapas cognitivos (De Castro, 1999); el dibujo como evocación del espacio (Licona, 2000) y el mundo de la vida; la fotografía acompañada de entrevista a profundidad (miradas entrevistadas) (Corona, 2002) y los grupos de discusión (entrevista colectiva) (Barral, 1998).

En este marco, desde el turismo también se ha suministrado todo un esquema metodológico para la demarcación de los imaginarios. Por ejemplo, en el trabajo de Godoy y Leite (2019), se realizó una investigación exhaustiva sobre el uso de metodologías de análisis de la imagen en estudios de turismo, a escala nacional e internacional, entre los años 2012 y 2017. Por medio de investigación exploratoria y bibliométrica en bases de periódicos extranjeros, se buscó verificar las principales metodologías que se utilizan en el campo del turismo. Como resultado se verificó que las investigaciones en turismo utilizan metodologías tradicionales, para analizar imágenes, tales como: semiótica y análisis de contenido. Otras más contemporáneas, como es el caso de la volunteer-employed photography, la antropología visual/fotoetnográfica, la foto elicitación, la técnica Zaltman Metaphor Elicitación (ZMET), y la iconografía. Cabe señalar que el uso de esas metodologías, en general en el área de gestión y marketing de destinos turísticos, se apoyó en otros métodos cualitativos conceptuados -entrevistas en profundidad y observación participante, por ejemplo - como forma de validar los resultados de la investigación.

Empero para esta investigación sobre imaginarios intersubjetivos e instituidos, se propone revisar una metodología horizontal, misma que intenta construir una autonomía de las voces, cuestión tan necesaria cuando se buscar dar cuenta de ciertas intersubjetividades.

\subsection{Metodología-horizontal para la demarcación de los imaginarios}

En la demarcación metodológica de las construcciones sociales denominadas imaginarios, se propone el uso de una metodología con enfoque cualitativo-horizontal. El enfoque cualitativo es propio, aunque no exclusivo, de la antropología, la sociología, la etnografía, la etnometodología y el interaccionismo simbólico, entre otros, debido a que se prima por un paradigma hermenéutico. En este sentido, Ruiz (2012) menciona que el análisis cualitativo surge de aplicar una metodología específica orientada a captar el origen, el proceso y la naturaleza de los significados que brotan de la interacción simbólica entre los individuos. Desde la perspectiva o análisis émico, que busca representar un punto de vista interior, desde el sujeto que vive los fenómenos y los significa, es decir el sujeto de estudio.

Y es que, siguiendo a Sara Corona (2017), la metodología horizontal es una "práctica investigativa para construir nuevo conocimiento a partir de la equidad discursiva, que en el proceso construye la autonomía de las voces que requiere la convivencia social" (2017, p.93). Dicha metodología, agrega Corona, es también un método que implica una teoría del conocimiento, de las condiciones y modalidades de construcción del conocimiento que siempre son dialógicas; no trata de la reflexividad ni de la colaboración, sino que, desde la horizontalidad, se abren puertas a nuevos conocimientos.

Por ello parece pertinente proponer una enfoque cualitativo-horizontal que permite comprender el proceso de simbolización o el conjunto de procedimientos mediante los cuales los sujetos dotan, intersubjetivamente, de sentido a la realidad, en una relación horizontal de compartir saberes, de construir conocimiento.

En este sentido vale preguntarnos ¿cuál debe ser la postura del investigador en esta metodología-horizontal? El sujeto-investigador no debe olvidar que el mundo de la vida cotidiana que investiga, donde existen los sujetos y objetos de estudio (Reguillo, 1998): a) es incoherente -no se le ofrece como un dato dado, es necesario construir el sistema de coherencias-, en palabras de Clifford Geertz, el análisis consiste en desentrañar las estructuras de significación y en determinar su campo social y su alcance (Geertz, 2006); pero siempre acompañado de ese sujeto con el que se ha decidido dialogar y compartir saberes. Así, b) es sólo parcialmente claro -la "naturalidad" con la que los actores desempeñan sus roles y ejecutan acciones u "ocultan" los significados y el sentido, por ello es necesario problematizar la claridad con la que éstos aparecen-. Por último, c) es contradictorio, las diferencias que existen entre el sostenimiento de una opinión y una acción contraria, aunque ello no significan que los actores "mientan" o que sean ilógicos. El mundo social es básicamente contradictorio y sujeto a una lógica de operación cotidiana. Empero, esto último se puede solventar si existe una intención real de compartir y construir de la mano de ese otro, que le a permitido al investigador incursionar en su mundo de la vida cotidiano. 
Bajo este panorama habría que revisar el enfoque y método, que nos permite acercarnos a esa realidad y dar cuenta de ella, me refiero a la etnografía. Pero una etnografía otra, más bien horizontal.

\subsection{Etnografía horizontal}

La etnografía tiene una triple acepción: enfoque, método y texto. Como enfoque constituye una concepción práctica de conocimiento que busca comprender los fenómenos sociales desde la perspectiva de sus miembros (Guber, 2017) y mostrarlos a través de una descripción densa (Geertz, 2006).

Lo que encara el etnógrafo es una multiplicidad de estructuras conceptuales complejas -es como tratar de leer un manuscrito extranjero-, donde muchas están superpuestas o enlazadas entre sí. Estructuras que son al mismo tiempo extrañas, irregulares, no explícitas, y a las cuales el etnógrafo debe integrarse de alguna manera (observación participativa), para captarlas primero y explicarlas después (Geertz, 2006), a través de una descripción densa, es decir etnográfica.

De manera que, siguiendo a Geertz, la descripción etnográfica presenta cuatro rasgos característicos: 1) es microscópica, 2) es interpretativa (de segundo y tercer orden ), 3) lo que interpreta es el flujo del discurso social, y 4) la interpretación consiste en tratar de rescatar "lo dicho" en ese discurso de sus ocasiones perecederas y fijarlo en términos susceptibles de consulta. Por eso la etnografía, es la interpretación de las culturas.

La interpretación del investigador o etnógrafo reconoce los marcos de significación dentro de los cuales los sujetos se mueven en colectivo. Sin embargo, "esta descripción densa debe ser coherente con lo que piensan y dicen los nativos, de modo que dicha descripción no es ni el mundo de los nativos, ni el modo en que ellos lo ven, sino una conclusión interpretativa que elabora el investigador" (Jacobson, 1991 en Guber, 2017, p.18). Pero, a diferencia de otros informes de investigación, esa conclusión proviene de la articulación entre la elaboración teórica del investigador y su contacto prolongado con las comunidades originarias (Guber, 2017).

En este sentido Geertz (2006) argumenta, que la función de la teoría es suministrar un vocabulario en el cual pueda expresarse lo que la acción simbólica tiene que decir sobre sí misma, es decir, sobre el papel de la cultura en la vida misma. De tal suerte que no es solamente interpretación lo que se desarrolla en el nivel más inmediato de la observación, también se desarrolla la teoría de la que depende conceptualmente la interpretación.

Ahora bien, la etnografía como método se determina por "el conjunto de actividades que suelen designarse como trabajo de campo, y cuyo resultado se emplea como evidencia para la descripción”(Guber, 2017, p.19), donde el trabajo de campo permite al investigador social o al etnógrafo, conocer otros mundos, que no sería posible comprender si no fuera a través de su propia exposición o inmersión en ellos. Para lo cual, además, debe utilizar ciertas técnicas e instrumentos como: la observación participante, la entrevista etnográfica y el registro.

\section{CONCLUSIONES}

Los enfoques vía los cuales se han analizado los imaginarios sociales, desde las ciencias cognitivas, las historiográficas y las antropológicas, y las ciencias sociales en general, poseen ciertos matices que permiten encontrar similitudes pero también dilucidar ciertas diferencias, mientras unos conceptualizan los imaginarios como imágenes mentales, otros argumentan que son objetivables a través de elementos tangibles, estáticos e institucionalizados. Sin embargo, los imaginarios intersubjetivos que se quieren demarcar en un primer acercamiento a una propuesta, parten del supuesto de que estos son concepciones dinámicas del mundo y de la realidad que forma el entorno histórico de sujetos concretos, más allá de las simples evocaciones estáticas y analíticas con las que comúnmente se delimitan a los imaginarios.

En este marco, el turismo se ha abordado particularmente desde concepciones positivistas, económicistas y capitalistas, pero en este momento quizá ninguna permite abordar adecuadamente los fenómenos contemporáneos, concretamente sobre turismo rural en comunidades indígenas, es decir desde los sujetos que vive, resisten y enfrentan los embates del turismo rural como forma particular de acumulación del capital y como mecanismo de mercantilización, no solo de la naturaleza sino de la vida. Es en función de lo anterior, que se invocan otras posibilidades de comprensión de los imaginarios sociales, que más bien ahora se proponen como intersubjetivos versus los instituidos del capitalismo.

En consecuencia los imaginarios intersubjetivos en las comunidades indígenas, no estan ajenos a la imposición de una violencia estructural y simbólica, desde los imaginarios instituidos capitalistas y colonizadores, que buscan 
subsumir a la comunidad en una reproducción de la vida inorgánica, a través de prácticas mercantiles, que cosifican al colectivo, sus bienes naturales y culturales, pero que además están debilitando su tejido social, donde es evidente la presencia de imaginarios instituidos y dominantes como la propiedad privada, el libre mercado, la acumulación por despojo, el desarrollo territorial, los programas de turismo rural, versus los imaginarios intersubjetivos de autonomía, autodeterminación, prácticas otras de reproducción de la vida, por mencionar algunas.

Así las comunidades indígenas en nuestro país han experimentado diversas transformaciones económicas, socioculturales y políticas, que han trastocado sus estructurales internas ( familia, territorio, religión, en síntesis su comunalidad). Muestra de ello es la fractura de sus vínculos comunitarios o dislocación de ellos, la alternacia de actividades económicas tradicionales con nuevas actividades productivas e incluso el abandono de las primeras, la disolución de referentes identitarios individuales y colectivos, y la modificación de las formas orgánicas de reproducción de la vida entre otras. Ello en un plano de imposición del modelo económico imperante, que busca modernizar el campo y homogeneizar actividades económicas desde la diversificación (pluriactividad) hacia la agroindustria o los servicios. Y que para el caso que nos ocupa, dicha diversificación descansa bajo la inserción del turismo rural-indígena, como alternativa de desarrollo para las suspuestamente atrasadas y debilitadas áreas rurales.

Sin embargo, como en la mayoría de proyectos con orientación vertical, la imposición no siempre genera resultados adecuados, por el contrario da evidencia de la invisibilidad en la que se encuentran las comunidades indígenas, usadas como herramienta para implementar programas gubernamentales, cumplir metas administrativas, atender intereses privados y transnacionales. He aquí donde la violencia estructural, institucional y colonia se hace presente.

Ya que de cara a las políticas neoliberales y al modelo económico predominante, se ha impuesto una nueva forma de organización y producción en las comunidades rurales e indígenas en las que predominan el cambio de actividades tradicionales, por una diversificación de las mismas, nueva ruralidad, que invita a ser parte del modelo pero en un contexto desigual frente a los grandes corporativos y transnacionales.

Por lo anterior es que queda pendiente aplicar esta propuesta sobre imaginarios intersubjetivos e instituidos en los referentes empíricos, para visibilizar y analizar lo que esta sucediendo en las comunidades indígenas, a raíz de la imposición o no del turismo rural en sus territorios. Sin embargo, dicha investigación se debe hacer desde un análisis crítico de los imaginarios intersubjetivos e instituidos, para reconocer las transformaciones y contradicciones en sus experiencias intersubjetivas frente a su realidad sociocultural, económica, ambiental y política que está siendo trastocada y violentada, pero que además ha sido invisibilizada, al no atender sus contextos situados y al no permitirles ejercer su autonomía y autodeterminación.

\section{REFERÊNCIAS}

Amirou, R. (2002a). De l'imagerie populaire à l'Imaginaire touristique. Revue Espaces, 199, p. 24-25.

Amirou, R. (2007b). Tourisme et postmodernité. Les métamorphoses de l'authenticité. Revue Espaces, 245, p.4653.

Aravena, A., y Baeza, M. A. (2015). Construcción socioimaginaria de relaciones sociales: la desconfianza y el descontento en el Chile post-dictadura. Revista de Moebio, 53, p. 147-157. https://doi.org/10.4067/S0717$554 \times 2015000200004$

Aravena Reyes, A., Cerda Zúñiga, C., Alcota Poblete, P. y Zañartu Canihuante, N. (2019). Identidad étnica mapuche e imaginarios sociales del bienestar en la región del Biobío, Chile. Psicologia y Sociedade, 31, p.1-20. https://doi.org/10.1590/1807-0310/2019v31186132

Baeza, M. A. (2003). Imaginarios sociales. Apuntes para la discusión teórica y metodológica. Revista de Ciencias Sociales y Humanidades, (64-65), p. 311-315.

Barral González, L.M. (1998). El empleo de grupos de discusión en la investigación social. En A. García Ballestero (Ed). Métodos y técnicas cualitativas en geografía social. Oikos-Tau.

Basulto Gallegos, O. F. (2020). Relevancia de los imaginarios sociales en la construcción de valor territorial turístico. Análisis de un caso de estudio comparado. Estudios y Perspectivas en Turismo, 29(3), p. 932-957.

Berdoulay, V. (2012). El sujeto, el lugar y la mediación del imaginario. En A. Lindón y D. Hiernaux (Eds.), Geografías de lo imaginario (pp. 49-64). Anthropos y UAM.

Castoriadis, C. (1997). El Imaginario Social Instituyente. Zona Erógena, 35, p. 1-9. 
Castoriadis, C. (2013). La instititución imaginaria de la sociedad. Fábula Tusquets Editores.

Claval, P. (2012). Mitos e imaginarios en la geografía. En A. Lindón y D. Hiernaux (Eds.), Geografías de lo imaginario (pp.29-48). Anthropos y UAM.

Cegarra, J. (2012). Fundamentos Teórico-Epistemológicos de los Imaginarios Sociales. Cinta moebio, 43, p. 1-13. https://doi.org/10.4067/S0717-554X2012000100001

Corona Berkin, S. (2017). Flujos metodológicos desde el Sur latinoamericano. La zona de la comunicación y las Metodologías Horizontales. Comunicación y Sociedad, No. 30, septiembre-diciembre, p. 69-106. https://doi.org/10.32870/cys.v0i30.6819

Corona Berkin, S. (2002). Miradas entrevistas. Aproximación a la cultura, comunicación y fotografía huichola. Universidad de Guadalajara.

Custodero, L. (2006). Being-with:The Resonant Legacy of Childhood's Creative Aesthetic. The Journal of Aesthetic Education, 3(22), p. 35-57. https://doi.org/10.1353/jae.2005.0015

Debarbieux, B. (2012). Los imaginarios de la naturaleza. En A. Lindón y D. Hiernaux (Eds.), Geografías de lo imaginario (pp.141-158). Anthropos y UAM.

De Castro Aguirre, C. (1999). Mapas cognitivos. Qué son y cómo explorarlos. Scripta Nova. Revista Electrónica de Geografía y Ciencias Sociales, 33, p. 1-20.

Dias, F., Marques, M.I., y Bachimon, P. (2011). In memoriam a tribute to Rachid Amirou. European Journal of Tourism, Hospitality and Recreation, 2(1), p. 5-18.

Dinerstein, A. (2017). Afirmación como Negatividad. Abriendo espacios para otra teoría critica. Coloquio marxismo abierto. 25 años del marxismo abierto: Reflexiones sobre teoría crítica y praxis revolucionaria. Del 16 al 20 de octubre de 2017. Posgrado en Sociología. Instituto de Ciencias Sociales y Humanidades "Alfonso Vélez Pliego". Benemérita Universidad Autónoma de Puebla. México.

Durand, G. (1994). L'Imaginaré. Gallimard

Durand, G. (2004). Las estructuras antropológicas del imaginario. Fondo de Cultura Económica.

Eloy Méndez Sáinz, E. y Velázquez García, M. A (2013). Turismo e imaginarios. El Colegio de Sonora.

Enriquez Acosta, J. A., Vargas, R. Y., y León Sarabia, C. A. (2017). Imaginarios sociales e impactos del turismo residencial en ciudades del Noroeste de México. (1 ed.) Universidad de Sonora.

Enríquez Acosta, J. y Vargas Ochoa, R.Y. (2015). Configuración de los imaginarios para la promoción turística en Álamos Sonora. Topofilia Segunda Época Revista de Arquitectura, Urbanismo y Territorios. Instituto de Ciencias Sociales y Humanidades “Alfonso Vélez Pliego” BUAP, 5 (1).

Enríquez Acosta, J., Guillén Lúgigo, M., Jaime, M. E. y Valenzuela, B. (2015). Imaginarios sociales de la comunidad, en el pueblo mágico de El Fuerte, Sinaloa, México. Imagonautas: revista interdisciplinaria sobre imaginarios sociales, 5 , p. $82-99$

Gastal, S. (2005). Turismo, imagens e imaginário. Aleph.

Geertz, C. (2006). La interpretación de las culturas. Gedisa.

Girola, L. y González, M. (2020). Imaginarios y representaciones sociales. Reflexiones conceptuales y una breve mención al estado del arte en México. En D. Hiernaux-Nicolas, M. O. García y R. A. V. Gómez. Los imaginarios sociales y el turismo. Universidad Panamericana, Campus México.

Godoy, K.E.; Leite, I.S. (2019). Turismo e fotografia: um estudo bibliométrico sobre o uso de metodologias de análise da imagem nas pesquisas em turismo. Revista Brasileira de Pesquisa em Turismo, 13(3), p.71-91. https://doi.org/10.7784/rbtur.v13i3.1573

Guber, R. (2017). La etnografía. Método, campo y reflexividad. Siglo XXI.

Hiernaux, D. (2012).Geografías de lo imaginario. Anthropos y UAM.

Hiernaux, D. (2002). Turismo e imaginarios. Cuaderno de Ciencias Sociales, 123, p. 7-32.

Hiernaux, D. (2007). Los imaginarios urbanos: de la teoría y los aterrizajes en los estudios urbanos. EURE, 33(99), p. 17-30. https://doi.org/10.4067/S0250-71612007000200003

Hiernaux, D., y González Gómez, C. I. (2015) Patrimonio y turismo en centros históricos de ciudades medias. ¿lmaginarios encontrados? URBS. Revista de Estudios Urbanos y Ciencias Sociales, 5(2), p. 111-125.

Holloway, J. (2015). Contra el dinero. Acerca de la perversa relación social que lo genera. Herramientas y BUAP. 
Husserl, E. (2005). Ideas relativas a una fenomenología pura y una filosofía fenomenológica. Libro Segundo: Investigaciones fenomenologías sobre la constitución. UNAM y Fondo de Cultura Económica.

Lacan, J. (2009). El estadio del espejo como formador de la función del yo [je] tal como se nos revela en la experiencia psicoanalítica. Siglo XXI.

Licona Valencia, E. (2000). El dibujo, la calle y la construcción imaginaria. Ciudades, 46, p. 25-33.

Lindón, A. (2012). ¿Geografías de lo imaginario o la dimensión imaginaria de las geografías del Lebenswelt? En A. Lindón y D. Hiernaux (Eds.), Geografías de lo imaginario (pp. 65-86). Anthropos y UAM.

Lythgoe, E. (2014). El papel de la imaginación en la memoria, la historia, el olvido de Paul Ricœur. Diánoia, 59(73), p. 73-88. https://doi.org/10.21898/dia.v59i73.82

Osorio González, R. (2020). Imaginarios sociales y nuevas habitualidades en los pueblos originarios, frente al turismo rural: una aproximación fenomenológica. Acta Mexicana de Fenomenología. Revista de investigación filosófica y científica, (5), p. 81-103.

Pintos, J. L. (2014). Algunas precisiones sobre el concepto de imaginarios sociales. Revista Latina de Sociología, (4), p. 1-11. https://doi.org/10.17979/relaso.2014.4.1.1217

Rabinovich, D. (1995). Lo imaginario, lo simbólico y lo real. UBA.

Reguillo, R. (1998). De la pasión metodológica o la (paradójica) posibilidad de la investigación. En M. Arauz, R. Sandoval y S. A. Sandoval (Eds.), Tras las vetas de la investigación cualitativa, Perspectivas y acercamientos desde la práctica. ITESO, México.

Rowles, G. (1978). Reflexiones sobre el Trabajo de Campo Experiencial. En D. Ley y M. S. Samuels (Eds.). Humanistic Geography. Prospects and problems (pp. 1-22). Croom Helm.

Ruiz Olabuénaga, J. I. (2012). Metodología de la investigación cualitativa. Universidad de Deusto.

Sánchez-Barranco Ruiz, A., Sánchez-Barranco Vallejo, P., y Sánchez-Barranco Vallejo, I. (2006). Reconstrucción histórica de la obra de Jacques Lacan. Revista de la Asociación Española de Neuropsiquiatría, 26(1), p. 107131. https://doi.org/10.4321/S0211-57352006000100007

Silva, A. (2004). Imaginarios urbanos: hacia el desarrollo de un urbanismo desde los ciudadanos. Metodología. Universidad Nacional de Colombia.

Silva, A. (2013). Imaginarios, el asombro social. Universidad Externado de Colombia.

Solares Altamirano, B. (2011). Gilbert Durand, imagen y símbolo o hacia un nuevo espíritu antropológico. Revista Mexicana de Ciencias Políticas y Sociales, $\quad$ (211), p. $13-24$. https://doi.org/10.22201/fcpys.2448492xe.2011.211.30241

Zamudio Vega, L. S. (2012). La arquitectura en los imaginarios turísticos. RIPS. Revista de Investigaciones Políticas y Sociológicas, vol. 11, núm. 2, 2012, pp. 145-158.

\section{Informação da Autora}

\section{Rebeca Osorio González}

Doctorante en Ciencias Sociales por la Facultad de Ciencias Políticas y Sociales de la Universidad Autónoma del Estado de México (UAEM). Profesora/Investigadora de Tiempo Completo, de la Facultad de Turismo y Gastronomía,UAEM. Perfil PRODEP.Editora de la revista El Periplo Sustentable (2017-2019). Miembro fundador de la Asociación Mexicana de Turismo Rural (AMEXTUR). Miembro de la Academia Mexicana de Investigación (AMIT) y de la Red Latinoamericana de Investigadores y Turismo (RedilesTur). Línea de investigación: Turismo rural e imaginarios sociales.

Contribución: Diseño de investigación, revisión de literatura, recopilación de datos y discusión de resultados.

E-mail: rosoriog@uaemex.mx

Orcid: https://orcid.org/0000-0001-8901-8124 